indexecomunicación | no 9 (3) 2019 | Páginas 115-138

E-ISSN: 2174-1859 | ISSN: 2444-3239 | Depósito Legal: M-19965-2015

Recibido el 08_07_2019 | Aceptado el 28_09_2019 | Publicado el 16_11_2019

\title{
EL NÚMERO MUSICAL EN LAS SERRES DE TELEVISIÓN: LA SINCRONÍA MUSICOVISUAL COMO CARACTERÍSTICA PRINCIPAL DE LAESCENA MUSICAL
}

MUSICAL PERFORMANCES IN TVSERIES: MUSICAL-VSUALSYNCHRONY AS THE MAINFEATUREOF THEMUSICAL SCENE

\section{Pedro Galeano Galea}

pedro.galeano@uca.es iD http://orcid.org/0000-0001-8999-6243

\section{Universidad de Cádiz}

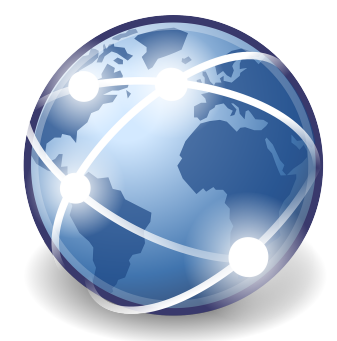

Para citar este trabajo: Galeano Galea, P. (2019). El número musical en las series de televisión: la sincronía musicovisual como característica principal de la escena musical. index.comunicación, 9(3), 115-138. 
Resumen: El número musical se ha convertido en un recurso usual en las series de televisión. Esta investigación señala tres objetivos: estudiar la aparición del número musical y sus características principales en la ficción televisiva; definir la tipología de música utilizada en dichas actuaciones; y, por último, señalar qué clase de sincronía musicovisual se emplea en la muestra seleccionada. En este estudio descriptivo se han empleado dos procedimientos: la revisión bibliográfica de fuentes actuales y el estudio de 76 casos de números musicales en diferentes episodios. Las series de televisión, en su mayoría en formato dramedia, incluyen uno o varios números musicales en algunos de sus episodios, tanto para homenajear al género del musical como para ofrecer nuevos contenidos a su público. En muchos casos se emplea la música preexistente y más concretamente la forma cover para ofrecer canciones interpretadas por el propio elenco de la serie. Una característica importante es la sincronía musicovisual en este tipo de escenas, siendo generalmente clasificada como unificadora y producida tanto por el fraseo, las muecas en el rostro de los personajes y sus movimientos corporales, como por el ritmo de montaje en la posproducción del capítulo. Palabras clave: ficción televisiva; series de televisión; número musical; sincronía musicovisual; dramedia.

Abstract: Musical performances have become a common resource in television fiction. The objectives of this research are to study musical performances and their main characteristics in television fiction; to define the type of music used in these performances; and, finally, to indicate what kind of musical-visual synchronisation is used in the selected samples. In this descriptive study, two procedures have been employed: the bibliographical review and the study of 76 cases of musical performances in different episodes. Television series, mostly in dramedy format, include one or several musical performances in some of their episodes, both as a tribute to the musical genre, as well as a way of offering new content to its audience. In many cases pre-existing music is used, and more specifically, the cover musical format, in order to offer songs performed by the same cast of the series. An important characteristic is the musical-visual synchronisation in these types of scenes. This synchrony is generally categorised as unifying, and it is produced by both the phrasing, facial gestures and body movements of the characters, and by the rhythm of editing in the post-production of the episode. Keywords: Television Fiction; Tv Series; Musical Performance; Music-Visual Synchronisation; Dramedy. 


\section{Introducción}

El género del musical ha experimentado grandes cambios desde su aparición a finales de los años veinte en la gran pantalla. Dicho género tiene como antecesor en muchos casos a los espectáculos de Broadway. En las últimas dos décadas se ha podido observar un uso bastante común del número musical como recurso para homenajear a este género, que hoy en día sigue en auge debido a las superproducciones cinematográficas y a los espectáculos musicales en los teatros.

El empleo de este recurso en la ficción televisiva, mayormente en el formato de la serie de televisión, es un claro ejemplo del arraigo cultural y la puesta en valor de este género. A su vez, una de las características primordiales del número musical es la gran cantidad de puntos síncronos entre el componente musical y el visual, también conocido como el fenómeno de la sincronía musicovisual. Por ello, este estudio pone de manifiesto las características esenciales dadas en los números musicales presentes en la ficción televisiva de las últimas dos décadas.

Es necesario aclarar que, a pesar de que algunos autores como Carrasco (2010) entienden la serie de televisión como sinónimo de teleserie, en esta investigación se empleará dicho término como un concepto paraguas que recoge todas las formas de ficción televisiva divisibles en capítulos. Por tanto, se incluirán formatos tales como la miniserie, la teleserie y la antología. Quedan fuera de dicho término esas ficciones televisivas autoconclusivas e indivisibles en episodios como son el telefilm y otras formas no mencionadas anteriormente. Se ha decidido emplear dicha manera de referirse a esta agrupación de formatos para facilitar la lectura del estudio, las referencias y estar más acorde con la categorización empleada en bases de datos como $\mathrm{IMDb}^{1}$ y páginas web, en las que tanto las miniseries como las antologías aparecen clasificadas bajo el nombre de «series de televisión».

\section{La relación sincrónica entre el componente musical y el visual en las series de televisión expuesta en el número musical}

\subsection{La ficción televisiva en las cadenas público-privadas de televisión y en las plataformas de 'streaming'}

En los últimos años las series de ficción han tomado relevancia en el espacio cultural de la sociedad. Esta cuestión no se debe a que los espectadores vean ahora más series de televisión que antes, sino a que se generan más discursos en torno a estas obras audiovisuales. Además, se han consolidado importantes prácticas culturales a su alrededor, estableciéndose su consumo como un hábito para la sociedad, y más concretamente, para los jóvenes. Por ello, se han originado diversas transformaciones tanto en la difusión y visualización de estos contenidos, como en los diferentes formatos que han surgido bajo el género de la ficción televisiva.

En la última década se han producido algunos cambios en la forma de consumo de estos productos audiovisuales. Con la aparición de las grabadoras digitales y, posteriormente, la existencia de un servicio de vídeo bajo demanda y su evolución hasta convertirse en

\footnotetext{
${ }^{1}$ IMDb se trata de una base de datos autorizada de películas, TV y contenidos de celebridades donde se encuentra almacenada todo tipo de información acerca de estos contenidos (https://www.imdb.com).
} 
plataformas de streaming, se ha observado que hoy en día se consume más contenido que nunca, pero empleando otras ventanas diferentes a la televisión comercial (Cascajosa, 2016). Tal es la importancia que reciben las nuevas tecnologías, que las productoras de las series ofrecen a los espectadores (a su vez, internautas) una serie de servicios de valor añadido que complementan su experiencia al consumir las series de televisión. Este tipo de servicios son «páginas webs que reflejan el universo de la serie, comentarios de episodios, entrevistas, tonos para móviles, salvapantallas y un largo etcétera» (Cascajosa, 2009: 30).

A pesar de la aparición de estas plataformas y el empleo de redes sociales de manera simultánea mientras se consume este producto, «la mayor parte del público sigue viendo las series mientras son emitidas en su pase original, que se mantiene como primera ventana de exhibición» (Cascajosa, 2016: 49). A pesar de esto, algunas series se emiten originalmente a través de las plataformas de streaming y mantienen la denominación de series de televisión. De hecho, son muchos los casos de series que empezaron a emitir sus primeras temporadas en los canales de televisión, pero los responsables de su difusión decidieron continuar emitiendo el resto de las temporadas en las plataformas anteriormente citadas.

Un claro ejemplo es Netflix, el servicio de videoclub que surgió en 1997 y que después favoreció la integración entre ordenador y televisor gracias a la visualización en streaming. Otra de las plataformas destacables es HBO.

Tanto en los canales de televisión públicos y privados, como en las principales plataformas digitales se pueden encontrar una variedad de géneros, entre los que destaca la ficción. Este género se puede definir como «destinado al entretenimiento de las audiencias a través de la narración de relatos inventados, cuya distribución en lata posibilita su programación en muy diversas franjas horarias de la parrilla» (Carrasco, 2010: 182). Este autor distingue tres formas básicas según su estructura narrativa: el telefilm, la miniserie y la teleserie.

El telefilm es un formato televisivo de ficción de carácter unitario consistente en la emisión de un relato autoconclusivo, salvo secuelas. A diferencia de la miniserie, formato con el que a veces se le confunde, no está organizado en capítulos (Gordillo, 2009). Por el contrario, se define la miniserie como aquel formato televisivo de ficción estructurado en escasos capítulos (dos o tres generalmente) y con un relato autoconclusivo, a excepción de que se realicen secuelas (Carrasco, 2010). Existen varias modalidades de la miniserie según la temática: narraciones procedentes de adaptación de novelas de ficción; biografias de personajes de distintos ámbitos de la cultura, la ciencia o cualquier otra parcela; acontecimientos históricos; y familiares (Gordillo, 2009).

Finalmente, el formato al que mayor atención se le presta es al de la teleserie. Se denomina teleserie a «la narración seriada de diferentes relatos de ficción, fragmentados en diferentes capítulos» (Carrasco, 2010: 183). El mismo autor añade que tiene un claro propósito comercial destinado al entretenimiento y que la duración de los capítulos viene definida tanto por la propia estructura de la parrilla de la cadena como por los hábitos de consumo de los espectadores. Presenta una clasificación de esta categoría en cinco formatos diferentes agrupados en base a la naturaleza de su contenido, es decir, en drama (soap opera, telenovela y teleserie dramática) y en comedia (sitcom o comedia de situación y dramedy o dramedia). 
Carrasco (2010) también confecciona una tabla en la que recoge todas las características de estos cinco formatos diferentes de teleseries teniendo en cuenta su horario habitual de emisión, el número de tramas, el carácter de la trama principal, el número de personajes, los contenidos paradigmáticos, el target al que va dirigido y la duración media de cada capítulo.

Tabla 1. Esquema conceptual final de los géneros y formatos de las series de ficción televisiva.

\section{Ficción televisiva: series}

\section{Teleserie de drama}

Series de estructura abierta o cerrada, cuyos contenidos de diferente naturaleza, no están orientados hacia el humor o la comedia como forma principal de entretenimiento.

\section{Telecomedia}

Series de estructura abierta y contenidos realistas, hacia el entretenimiento a través del humor y la comedia.

\begin{tabular}{|c|c|c|c|c|c|}
\hline & Soap opera & Telenovela & Serie dramática & Sitcom & Dramedy \\
\hline $\begin{array}{l}\text { Horario } \\
\text { habitual de } \\
\text { emisión }\end{array}$ & $\begin{array}{l}\text { Daytime, } \\
\text { sobremesa }\end{array}$ & $\begin{array}{l}\text { Preferentemente } \\
\text { tarde, sobremesa e } \\
\text { incluso prime time }\end{array}$ & Prime time & $\begin{array}{l}\text { Sobremesa, tarde, } \\
\text { acces prime time }\end{array}$ & $\begin{array}{l}\text { Sobremesa, } \\
\text { prime time }\end{array}$ \\
\hline $\begin{array}{l}\text { Periodicidad } \\
\text { habitual }\end{array}$ & Diaria & $\begin{array}{l}\text { Diversa, pero } \\
\text { regular }\end{array}$ & Semanal & Generalmente diaria & Semanal \\
\hline $\begin{array}{l}\text { Número de } \\
\text { tramas }\end{array}$ & Múltiples & Una principal & $\begin{array}{l}\text { Una principal y varias } \\
\text { secundarias por } \\
\text { capítulo (no son } \\
\text { necesarias, aunque } \\
\text { sí frecuentes, las } \\
\text { tramas de largo } \\
\text { recorrido) }\end{array}$ & $\begin{array}{l}\text { Una principal y varias } \\
\text { secundarias por capitulo } \\
\text { (no son necesarias tramas } \\
\text { de largo recorrido) }\end{array}$ & $\begin{array}{l}\text { Una principal y } \\
\text { varias } \\
\text { secundarias de } \\
\text { largo recorrido. } \\
\text { Una principal y } \\
\text { varias } \\
\text { secundarias por } \\
\text { capítulo }\end{array}$ \\
\hline $\begin{array}{l}\text { Carácter de } \\
\text { la trama } \\
\text { principal }\end{array}$ & Abiertas & Cerrada & $\begin{array}{l}\text { Del capítulo, } \\
\text { autoconclusiva (se } \\
\text { incorporan poco a poco } \\
\text { elementos de } \\
\text { continuidad de largo } \\
\text { recorrido) }\end{array}$ & $\begin{array}{l}\text { Del capítulo, } \\
\text { autoconclusiva }\end{array}$ & $\begin{array}{l}\text { Combinación de } \\
\text { tramas abiertas } \\
\text { de larga duración } \\
\text { con tramas } \\
\text { autoconclusivas } \\
\text { en cada capítulo }\end{array}$ \\
\hline $\begin{array}{l}\text { Número de } \\
\text { personajes }\end{array}$ & $\begin{array}{l}\text { Repartos } \\
\text { corales } \\
\text { susceptibles } \\
\text { de variación }\end{array}$ & $\begin{array}{l}\text { Reparto cerrado: } \\
\text { una pareja } \\
\text { protagónica y } \\
\text { varios secundarios } \\
\text { fijos }\end{array}$ & $\begin{array}{l}\text { Repartos corales } \\
\text { susceptibles de } \\
\text { variación }\end{array}$ & $\begin{array}{l}\text { Repartos corales, aunque } \\
\text { de escasos personajes, y } \\
\text { cerrados (ocasionalmente } \\
\text { puede haber alguna } \\
\text { incorporación o variación) }\end{array}$ & $\begin{array}{l}\text { Repartos corales } \\
\text { susceptibles de } \\
\text { variación }\end{array}$ \\
\hline $\begin{array}{l}\text { Contenidos } \\
\text { paradigmáticos }\end{array}$ & $\begin{array}{l}\text { Relaciones } \\
\text { humanas } \\
\text { desde } \\
\text { los } \\
\text { sentimientos }\end{array}$ & $\begin{array}{l}\text { Historias de amor } \\
\text { con final feliz (amor } \\
\text { como recompensa, } \\
\text { triunfo del bien } \\
\text { sobre el mal) }\end{array}$ & $\begin{array}{l}\text { Diversos: acción, } \\
\text { suspense, misterio, } \\
\text { emociones, conflictos } \\
\text { personales }\end{array}$ & $\begin{array}{l}\text { Enredos, malentendidos y } \\
\text { situaciones comprometidas } \\
\text { tomadas de lo cotidiano }\end{array}$ & $\begin{array}{l}\text { Revisión en clave } \\
\text { de humor de los } \\
\text { contenidos de la } \\
\text { soap opera }\end{array}$ \\
\hline Target & $\begin{array}{l}\text { Mujeres, } \\
\text { amas de } \\
\text { casa }\end{array}$ & Adulto & Adulto & $\begin{array}{l}\text { Todos los públicos, } \\
\text { aunque es cada vez más } \\
\text { frecuente la segmentación }\end{array}$ & $\begin{array}{l}\text { Todos los } \\
\text { públicos, aunque } \\
\text { es cada vez más } \\
\text { frecuente la } \\
\text { segmentación }\end{array}$ \\
\hline $\begin{array}{l}\text { Duración } \\
\text { media de cada } \\
\text { capítulo }\end{array}$ & $50-60 \mathrm{~min}$. & $\begin{array}{l}\quad 35-50 \mathrm{~min} . \\
\text { Siendo habitual } \\
\text { emisiones dobles }\end{array}$ & $45-60 \mathrm{~min}$ & 20-30 min. & 50-75 min. \\
\hline
\end{tabular}

Fuente: Carrasco (2010: 194). 
Existen también otras formas de ficción televisivas no recogidas por dicho autor. Esta es, por ejemplo, la antología. Dicho formato se puede definir como «un producto televisivo que posee capítulos totalmente independientes» (Gordillo, 2009: 140). Las más populares de la historia han sido las series producidas por Alfred Hitchcock, aunque actualmente se pueden encontrar ejemplos de series antológicas como Black Mirror (Channel 4, 2011-2014 y Netflix, 2016-2019), la cual emplea capítulos autoconclusivos y con personajes diferentes; American Horror Story (FX, 2011-2019), que emplea en cada una de sus temporadas tramas diferentes con personajes distintos realizados por el mismo elenco original; y Love, Death \& Robots (Netflix, 2019), la cual presenta capítulos que son hibridaciones tanto de todo tipo de formatos, como de la naturaleza de sus contenidos ${ }^{2}$ (algunos capítulos son catalogados como dramáticos, mientras que otros son considerados cómicos) y duración irregular en sus episodios.

A continuación, se presenta una tabla resumen de las tipologías de género de la ficción televisiva en las que se podrán clasificar los diferentes casos analizados en este estudio:

Tabla 2. Clasificación de la ficción televisiva analizada en este estudio según su género y formato.

\begin{tabular}{|l|l|l|}
\hline \multicolumn{2}{|l|}{ Miniserie } \\
\hline \multirow{4}{*}{ Antología } & \multirow{3}{*}{ Serie de televisión } & Soap opera \\
\cline { 3 - 3 } & & Telenovela \\
\cline { 3 - 3 } & & Serie dramática \\
\cline { 3 - 3 } & Telecomedia & Comedia de situación \\
\cline { 3 - 3 } & & Dramedia \\
\hline
\end{tabular}

Fuente: elaboración propia a partir de la clasificación presentada por Carrasco (2010).

Finalmente, tanto los expertos del mundo de la ficción televisiva como el público son conscientes de que la calidad de las series y sus guiones a veces son mejores que las películas exhibidas en los cines. Por ello, al ser un buen vehículo capaz de empatizar y conectar con su público, la industria musical se ha aprovechado de dicha circunstancia realizando en las series de televisión acciones de publicidad efectiva para dar a conocer a nuevos solistas y bandas (Padilla y Requeijo, 2011).

\subsection{El elemento musical en las series de televisión}

La funcionalidad de la música en la ficción televisiva siempre ha estado en el punto de mira de los profesionales del sector. En la serie de televisión se emplea la música como: acompañamiento de la acción, un elemento que conecta con el público, y/o una forma publicitaria para hacer famosos a los nuevos cantantes y para vender sus temas (Padilla y Requeijo, 2011), ya sea en disco o en formato MP3 en tiendas de contenidos multimedia y reproducción como iTunes.

Olarte (2010) comenta que, generalmente, toda esta labor se encontrará en el departamento de ambientación musical, el cual no solo se centra en la creación de las sintonías, cabeceras y

\footnotetext{
${ }^{2}$ Carrasco (2010: 183) también agrupa los formatos en base a la naturaleza de sus contenidos, es decir, si se trata de un drama 0 una comedia.
} 
ráfagas, sino también en la utilización de melodías preexistentes que tienen la finalidad predominantemente expresiva. Aunque esto no siempre ocurre, en ocasiones hay un compositor musical que se encarga de crear la ambientación para la serie en concreto.

Algunas veces la música tomará relevancia más allá de ser una mera acompañante del propio capítulo de la serie, como es el caso de Gossip Girl (The CW, 2007-2012) donde se emplean canciones de bandas y solistas de Nueva York porque es la ciudad donde se origina la trama, o Grey's Anatomy (ABC, 2005-2019), la cual emplea títulos de canciones para la denominación de sus episodios. Destaca también el ejemplo de la serie Mad Men (AMC, 20072015) que usa una banda sonora de la década de los años sesenta para facilitar que los aficionados de la serie, incluso si no han nacido en dicha fecha, puedan sentirse parte de la época a la que se hace alusión (Padilla y Requeijo, 2011).

En la ficción televisiva se puede emplear tanto música original o incidental como música preexistente. La música original es aquella que se encarga a un compositor para ser parte de la banda sonora de una pieza audiovisual, mientras que la música preexistente es un tema que ya existe en el mercado profesional y que para su utilización es necesario obtener los permisos del compositor y/o editor fonográfico (Guijarro y Muela, 2003).

Esta es la primera clasificación de la música que se empleará en esta investigación para aplicarse en el estudio de los casos. En cuanto a la música original, se pueden encontrar tanto canciones originales creadas para la propia serie como la banda sonora instrumental. En la mayoría de los casos la sintonía o main title theme suele ser también una composición original, la cual se puede encontrar con letra (canción) o sin ella (banda sonora). A continuación, se definirá esta tipología de música empleada en la ficción de televisión y, más concretamente, en las series.

La sintonía es una pieza musical que acompaña a la secuencia inicial de títulos, también conocida como opening. Esta pieza está asociada directamente con la serie y marca acústicamente su entrada en el contexto del flujo sonoro televisivo. Las tres funciones principales que cumple son la apelativa, la preparatoria y la de identificación (Zuazu y López, 2014). Estas breves composiciones tienen una duración que suele oscilar entre 0:37' y 4': 35" (Olarte, 2010).

Las sintonías remiten a la serie desde la primera emisión y sus características (ritmo, melodía y género), así como la letra en el caso de que se trate de una canción, definen a grandes rasgos tanto el tono general como el género audiovisual del que se trata, al mismo tiempo que se apela a un target concreto (Zuazu y López, 2014). Entre los compositores de esta forma musical empleada en las series figuran músicos «de concierto»; compositores emblemáticos para la música de cine; arreglistas profesionales y grandes compositores; músicos que se han especializado en repertorio sefardita y otras culturas; ambientadores musicales; o músicos que triunfaron en la canción pop (Olarte, 2010).

A partir de la sintonía, generalmente, se compone el resto de la música incidental, ya sea mediante la fragmentación, repetición, variación o desarrollo de los elementos reconocibles de esta breve pieza que a veces podrá llegar a funcionar como leitmotivs de los personajes principales (Zuazu y López, 2014). Un ejemplo de ello es el leitmotiv empleado para 
acompañar a la protagonista de la serie El tiempo entre costuras (Antena 3, 2013-2014), como señalan García y Johnson (2015). El tema musical que acompaña al personaje de Sira Quiroga ${ }^{3}$ está inspirado en compositores españoles como Isaac Albéniz (1860-1909) y Manuel de Falla (1876-1946). Además, "aparece siempre en forma de música extradiegética y acompaña al personaje de Sira en aquellas escenas que suponen un punto de inflexión para ella" (García y Johnson, 2015: 116).

Sin embargo, otro tipo de música empleada en las series de televisión será la música preexistente. Esta tipología la componen aquellos temas ya compuestos previamente a la fecha en la que se produjo la pieza de ficción en cuestión.

Puesto a que no existe una subclasificación de la música empleada en las series de televisión. Se han seleccionado las diferentes formas musicales que se pueden encontrar en una serie teniendo en cuenta las clasificaciones que presentan autores tales como Guijarro y Muela (2003), Olarte (2010) y Palencia-Lefler (2009). Dichos autores se centran en la música publicitaria, por lo cual se excluirían aquellos formatos en relación con la música propia de los anuncios, como es el caso del jingle, "un mensaje publicitario hecho canción" (Guijarro y Muela, 2003: 89).

Por lo tanto, las subcategorías existentes dentro de la música preexistente serán los formatos musicales tales como: el fono/master, el cover $^{4}$, las adaptaciones de temas ya existentes y las melodías de archivo (Olarte, 2010). Serán estos formatos, juntos a los de la música original (canción original, banda sonora y tema instrumental original), los que formen las tipologías de la segunda clasificación que se aplicará en este estudio.

En relación con el tipo de música que se emplea en las series, Quiles y Herrera (2000: 172) realizan un análisis de las músicas más utilizadas en este tipo de programas y las «estructuran en cuatro niveles, que por orden de mayor a menor presencia son: pop-rock o similar; música dance o similar; música de ambiente con melodías pegadizas y textura anodina; clásica o similan». Los autores Zuazu y López (2014: 17) también mencionan que las «canciones de música pop representan la inmensa mayoría de las músicas prexistentes que [...] deben ser escuchadas atentamente y establecen un tipo de relación distinta con el espectador y con la trama»>. Además de que, como ya se menciona anteriormente, tanto los grupos como los solistas emplean la serie de televisión para dar a conocer y promocionar sus nuevos temas y singles. Un buen ejemplo de ello serán los temas 'Chasing cars' de Snow Patrol (Eyes Open, 2006), y 'How to save a life' del grupo The Fray (How to Save a Life, 2005), ambos empleados en el capítulo 18 de la temporada siete de la serie Grey's Anatomy (ABC, 2005-2019), los cuales lanzaron a ambos grupos a lo más alto de las listas de iTunes (Padilla y Requeijo, 2011).

Según Moschini (2011) los autores de las series de televisión deciden usar los covers de una canción en vez de su versión original debido a que el significado general de la pieza musical puede ser cambiado por los arreglos instrumentales y las actuaciones de los cantantes, independientemente de que se mantenga la letra original.

\footnotetext{
${ }_{3}^{3}$ Sira Quiroga, interpretada por Adriana Ugarte, es la protagonista de El tiempo entre costuras (Antena 3, 2013-2014).

${ }^{4}$ El cover es «una forma musical que versiona una canción o una música instrumental conocida, cambiándole los arreglos musicales y el intérprete, sin modificar el texto» (Palencia-Lefler, 2009: 101).
} 
Aunque es cierto que «la música incidental está mucho más presente cuantitativamente que las músicas preexistentes (...) es notable el modo en que esta última despliega su enorme eficacia y poder tanto en los ámbitos narrativos como afectivos» (Zuazu y López, 2014: 17).

Para terminar, la música en la escena audiovisual puede darse en el tiempo y el espacio diegético, es decir, en la pantalla se puede observar la fuente de la que proviene la música; y, en tiempo y espacio extradiegético o no diegético, es decir, que la fuente se encuentre fuera del espacio de la imagen y del tiempo de la acción (Alten, 2008). En el primer caso, la música diegética se podrá dar en las series cuando un personaje presente en la escena cante o toque algún instrumento, mientras que la música extradiegética se empleará en la mayor parte del capítulo con el empleo de la banda sonora. En definitiva, la música en la serie «se hace presente de las formas más diversas: diegética, no diegética, cantada por los personajes, con artistas invitados, introduciendo números musicales, en situaciones reales o fantásticas») (García, 2013: 205). Esta clasificación basada en la aparición en escena de la fuente de la que procede la música también se aplicará en el estudio de los casos.

Con el fin de orientar al lector en lo recorrido hasta ahora sobre las clasificaciones abarcadas, y en forma de esquema para una mayor comprensión de las tipologías de música de interés para el estudio, se ofrece, a modo de guía, una tabla resumen de todas las clasificaciones de la música empleada que se aplicarán en el análisis de los casos seleccionados:

Tabla 3. Clasificación de la música empleada en los números musicales de la ficción televisiva.

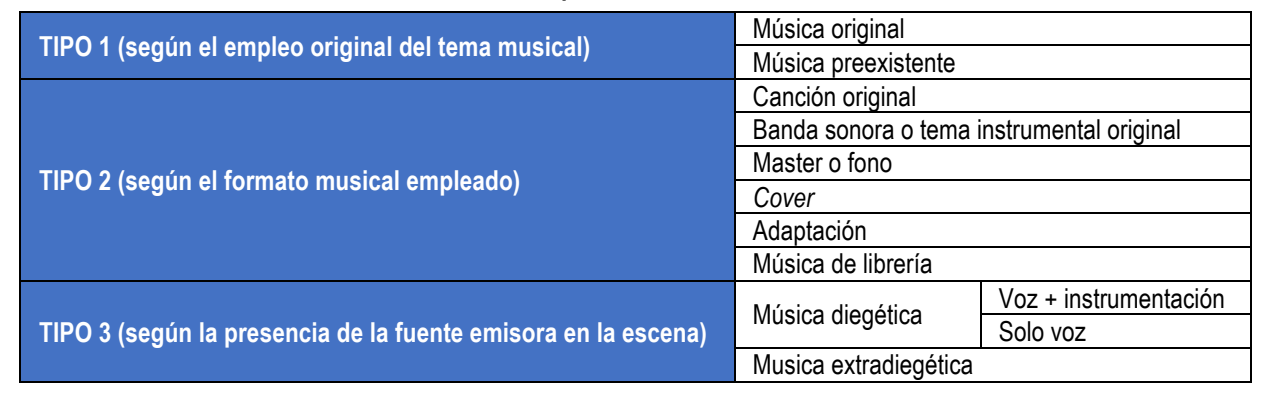

Fuente: elaboración propia a partir de las clasificaciones presentadas por Guijarro y Muela (2003), Olarte (2005), Alten (2008) y Palencia-Lefler (2009).

\subsection{El número musical como encuentro síncrono perfecto entre la música y la imagen}

Como se menciona en los apartados anteriores, la música toma un papel muy relevante en la ficción televisiva. La vinculación de este elemento junto con el componente visual a veces es tan cercana que se origina el fenómeno conocido como sincronía musicovisual. Se puede definir dicho fenómeno como el encuentro síncrono entre un instante sonoro musical y un instante visual debido a la coincidencia en fraseo o rostros, ritmo de montaje, movimientos (corporales o de algún objeto) u otro motivo, originado en cualquier momento dentro de la duración, en este caso, del número musical (Leguizamón, 2001; Rodríguez, 2001). 
Sedeño (2008) afirma que mediante la sincronía y los puntos de sincronización se pueden crear una gran cantidad de efectos narrativos y expresivos, así como conducir la atención visual hacia un hecho que coincide con el sonido que se escucha. Además, a través de las palabras de la autora se puede entender que la sincronía musicovisual mejora la percepción y experiencia del receptor ante una pieza audiovisual.

Se puede considerar como una primera clasificación tipológica la presentada por Leguizamón (2001), quien diferencia tres formas de que se produzca la sincronía musicovisual: por rostros y fraseo vocal o por la actuación instrumental; por los movimientos corporales (se incluirían aquí tanto personas, como objetos, trazos gráficos, e incluso leyendas referidas a cuerpo textuales); y, por último, dada por el ritmo de montaje, es decir, por cortes, fundidos, pliegues digitales, múltiples planos, etc. Esta primera clasificación tipológica hace referencia a la forma en la que se origina dicha sincronía entre la música y la imagen presentada en la pieza audiovisual.

Por otro lado, una segunda clasificación que se puede tener en cuenta es la que presenta Chion (1993) y Rodríguez (2001). Ambos autores señalan diferentes grados de sincronía, entre los que se encuentran: una sincronía unificadora, cuando se trata de una síncresis muy precisa; una estética, en el caso de que se diera un margen escaso de precisión; y una casual, en casos esporádicos e imprevisibles.

Sedeño (2008: 129) explica que la sincronía unificadora «se trata de una sincronización permanente y precisa, en la que el espectador percibe que la visión de la fuente sonora y el sonido están tan estrechamente imbricados que acepta este vínculo como natural, a pesar de basarse en un efecto artificial». Es decir, generalmente este tipo de sincronía se dará cuando se emplee en una producción una música del tipo diegética.

En este estudio se aplicarán las dos clasificaciones señaladas anteriormente y que se recogen a modo de resumen en la siguiente tabla:

Tabla 4. Clasificación principal de la sincronía musicovisual en los números musicales de la ficción televisiva.

\begin{tabular}{|l|l|}
\hline \multirow{2}{*}{ TIPO A (según cómo se origina la sincronía) } & Fraseo (labios) / Rostro (muecas al cantar) / Instrumento musical \\
\cline { 2 - 2 } & Movimiento de elementos y movimiento corporal de figurantes \\
\cline { 2 - 2 } & Ritmo del montaje de los planos y secuencias \\
\hline \multirow{2}{*}{$\begin{array}{l}\text { TIPO B (según la precisión de los puntos } \\
\text { síncronos) }\end{array}$} & Unificadora \\
\cline { 2 - 2 } & Estética \\
\cline { 2 - 2 } & Casual \\
\hline
\end{tabular}

Fuente: elaboración propia a partir de las clasificaciones de Chion (1993), Leguizamón (2001) y Rodríguez (2001).

Este fenómeno, que estrecha lazos entre el componente visual y el musical, se puede observar claramente en las series de televisión, más concretamente, en el número musical. Este tipo de número es un 'nuevo' recurso inspirado en categorías clásicas y empleado por los guionistas para sorprender a su público (García, 2013: 205).

El musical es uno de los géneros cinematográficos que más versatilidad ha experimentado desde su lanzamiento a finales de los años veinte, o que radica en su esencia es la música que, junto con el texto y la danza, consigue amalgamar una historia. Ésta, presentada al espectador 
con una elaborada preparación escénica, es la clave del musical: la coreografía, el decorado, el vestuario, la luz y el color (Olarte, 2005). Como homenaje a este género, algunas series introducen capítulos musicales completos o emulan números de los musicales de Broadway de forma esporádica.

La mayoría de las veces la música se introduce de forma diegética a través de personajes cantando a capella, y se justifica la inclusión de un número musical por tratarse de situaciones, por ejemplo, en las que se ensaya una canción por un grupo, se representa una actuación en un escenario o se realiza un baile en una escuela de danza. En este sentido, «se trataría de un recurso similar al utilizado en el tipo de musical backstage, en el que se explica la introducción del número musical porque es parte de un show o un ensayo del mismo» (García, 2013: 211).

Algunos autores como Stilwell (2003) han estudiado este tipo de número en las comedias de situación o sitcom. Para él, tanto las comedias como los musicales presentan estructuras bastante rígidas y el placer se encuentra en lo superficial, pero a veces el propio número musical puede funcionar como una broma en sí mismo.

García (2013) comenta que hay dos formas de introducir un número musical. Una forma es mediante una manera realista, justificándose como anteriormente se ha comentado, mediante parte de un show o un espectáculo. Otra forma sería la de integrar el número musical dentro del argumento, es decir, como un vehículo para que los personajes expresen sus sentimientos. Stilwell (2003) reconoce que a veces el número musical tiende a ser una suspensión de un momento en el tiempo, es decir, en algunos casos se puede encontrar que tras un número musical en un capítulo de la serie la acción se retoma donde se había quedado antes de iniciar dicho número.

A veces, el musical deja de ser un número esporádico en un capítulo y toma mayor relevancia siendo el núcleo de la serie al completo. Un ejemplo de ello es Glee (Fox, 20092015), una serie de formato enteramente musical. «Sus canciones han dado lugar a más de una decena de discos y sus actores protagonistas, casi todos adolescentes, han hecho varias giras de conciertos por todo el país» (Padilla y Requeijo, 2011: 77).

Para autores como Moschini (2011), en los números musicales las letras de las canciones son el sonido más destacado o, que al menos, comparten la misma importancia que los diálogos de la pantalla. El hecho de que estas letras se escuchen claramente permite al público que las asocie con las imágenes que ve. Para este mismo autor, los elementos que influyen en el proceso narrativo son: el tipo de texto elegido (la canción o tema interpretado), la versión de la canción (por ejemplo, un cover en vez de la versión original), y la parte de la canción que se reproduce.

Algunas de estas características señaladas serán las que se encuentren en el estudio de casos múltiples presentado en el epígrafe dedicado a los resultados de esta investigación.

\section{Metodología}

El objeto de este estudio es analizar el empleo del número musical en las series de televisión y observar las características del mismo en relación con el fenómeno de la sincronía musicovisual. La realización de esta investigación tiene un triple objetivo: en primer lugar, 
estudiar la aparición del número musical y sus características principales en la ficción televisiva con relatos fragmentados en capítulos emitida en España, ya sea en cadenas de televisión públicas y privadas, como en las principales plataformas de streaming para la visualización de este tipo de contenidos en los últimos 20 años. Un segundo objetivo es definir la tipología de música utilizada en los números musicales de las ficciones señaladas en el primer objetivo. Un tercer y último objetivo es señalar qué clase de sincronía musicovisual se emplea en los números musicales seleccionados.

El diseño de la metodología es del tipo descriptivo al tratarse de una investigación aplicada. Se podría organizar en dos partes bien diferenciadas que implican la utilización de una doble metodología y la división del estudio en dos etapas. La primera consiste en una revisión bibliográfica de fuentes secundarias, tanto obras monográficas como artículos científicos actuales que abordan el tema investigado. Por otro lado, en la segunda etapa se ha empleado un estudio de casos múltiples.

Las unidades de muestreo para este estudio son los capítulos de las diferentes series de televisión. Para la recolección de la muestra de los casos se han seleccionado diferentes requisitos que las piezas de ficción televisiva seleccionadas deberán cumplir:

1. Ser un formato televisivo de ficción compuesto por más de un capítulo. Es decir, se incluirán en la población las formas de ficción tales como las teleseries, las miniseries y las antologías. Por tanto, quedarán excluidos el formato del telefilm y las formas no mencionadas anteriormente.

2. Incluir al menos un número musical en alguno de sus capítulos. Es decir, quedan excluidos de la población de este estudio cualquier serie que no contenga un número musical según la definición de este término dada en esta investigación.

3. Haber sido emitida en las cadenas de televisión públicas o privadas de España, o en su lugar, en las tres principales plataformas de streaming actuales (Netflix, HBO y Amazon Prime Video) para la visualización de series. Por tanto, se excluyen todas esas series cuyos capítulos donde se presenten números musicales no hayan sido aún emitidos en España o pertenezcan a otras plataformas no nombradas.

4. Disponer de una versión doblada al español de sus capítulos. El tema o canción escogida para el número musical no tendrá que estar doblado necesariamente, pero los diálogos realizados por los personajes que forman parte del elenco del capítulo analizado sí deberán estar doblados al idioma español. A su vez, se considerarán también como parte de la población los capítulos de series producidas por países hispanohablantes, siempre y cuando se cumplan los demás requisitos establecidos. Ejemplo de esta última aclaración son las series: La casa de las flores (Netflix, 2018-2019), una ficción de México, y la serie musical argentina, Go! Vive a tu manera (Netflix, 2019), las cuales se emiten en la plataforma Netflix. 
5. El año de emisión del capítulo seleccionado en el que se presente el número musical en cuestión deberá ser superior al año 2000. Por tanto, quedan excluidas de la población aquellas series que presentan números musicales en capítulos emitidos en la fecha anterior al 1 de enero del año 2000. Por ejemplo, el capítulo especial musical titulado 'The bitter suite' $(3 \mathrm{x} 12)$ de la serie Xena: Warrior Princess (Syfy, 1995-2000), traducida en España como Xena: la princesa guerrera, se emitió en 1998. Por ello, este capítulo de serie queda fuera de la población establecida para el estudio.

6. No podrá ser una serie catalogada como animación o 'adultoon', ni ser una serie producida para su emisión en canales de contenidos únicamente infantiles. En las series de televisión dirigidas a un público infantil es muy común emplear números musicales en los que los personajes canten y/o bailen. Algunos ejemplos de estas series que quedan excluidas de la población de estudio son: The Simpsons (Fox, 1989-2019), Family Guy (Fox, 1999-2019), Hannah Montana (Disney Channel, 2006-2011), Phineas and Ferb (Disney Channel, 2007-2015), Adventure Time with Finn \& Jake (Cartoon Network, 2010-2018), y Tuca \& Bertie (Netflix, 2019).

Finalmente, la muestra obtenida está compuesta por 76 capítulos de series en los que se presenta un número musical. Es importante aclarar que en aquellas series de género musical o que suelen presentar en la mayoría de sus capítulos a lo largo de la temporada números musicales se ha analizado el primer episodio o capítulo piloto. Sin embargo, existe la excepción de algunos casos concretos en los que se ha seleccionado otros episodios diferentes del piloto por la relevancia y el interés que pueda aportar a esta investigación, como es el caso de la serie Glee (Fox, 2009-2015), Smash (NBC, 2012-2013) o Vinyl (HBO, 2016).

Tras tener en cuenta todos los requisitos señalados se han recopilado y seleccionado los capítulos de las diferentes series a través de la información recuperada de bases de datos como $\mathrm{IMDb}$, y otras fuentes secundarias.

A continuación, se expone en un cuadro los setenta y seis capítulos de series seleccionados que formarán la muestra de este estudio. Las series se presentan en su título original, ordenadas según la fecha de emisión, y acompañadas de la plataforma y el año de su primera y última emisión. Además, se añade el número de la temporada y del capítulo al que pertenecen el número musical o los números musicales, en caso de tratarse de un episodio especial.

\footnotetext{
${ }^{5}$ Los 'adultoon' son dibujos animados para adultos cuyas características principales son: el empleo de formas y colores llamativos, el uso de elementos de ironía y cinismo, las referencias culturales, los chistes ambiguos y las tramas complejas que conquistan a espectadores de más edad (Gordillo, 2009).
} 
indexocomunicación| número monográfico 9(3), 2019 Intersecciones televisivas

Tabla 5. Lista de episodios de series de televisión analizadas.

\begin{tabular}{|c|c|c|}
\hline Serie de televisión & $\begin{array}{c}\text { Plataforma, } \\
\text { año de primera y última emisión }\end{array}$ & Episodio \\
\hline The X-Files & Fox, $1993-2018$ & $9 \times 13$ \\
\hline Sabrina the teenage witch & ABC, $1996-2000$ y The WB, 2000-2003 & $7 \times 10$ \\
\hline Ally McBeal & Fox, 1997-2002 & $3 \times 21$ \\
\hline $\mathrm{Oz}$ & HBO, 1997-2003 & $5 \times 06$ \\
\hline Buffy the Vampire Slayer & The WB, 1997-2001 y UPN, 2001-2003 & $6 \times 07$ \\
\hline That '70s Show & Fox, 1998-2006 & $4 \times 24$ \\
\hline Malcolm in the Middle & Fox, 2000-2006 & $2 \times 13$ \\
\hline Scrubs & NBC, 2001-2008 y ABC, 2009-2010 & $6 \times 06$ \\
\hline Un paso adelante & Antena 3, 2002-2005 & $1 \times 01$ \\
\hline Two and a half men & CBS, 2003-2015 & $10 \times 13$ \\
\hline Desperate Housewives & ABC, 2004-2012 & $1 \times 11$ \\
\hline House M. D. & Fox, 2004-2012 & $7 \times 15$ \\
\hline Paco y Veva & La 1 (TVE), 2004 & $1 \times 01$ \\
\hline Grey's Anatomy & ABC, 2005-2019 & $7 \times 18$ \\
\hline Los Hombres de Paco & Antena 3, 2005-2010 & $4 \times 01$ \\
\hline How I met your mother & CBS, 2005-2014 & $5 \times 12$ \\
\hline Bones & Fox, 2005-2017 & $5 \times 19$ \\
\hline The Office & NBC, 2005-2013 & $7 \times 03$ \\
\hline Supernatural & The WB, 2005 y The CW, 2006-2019 & $10 \times 05$ \\
\hline 30 Rock & NBC, $2006-2013$ & $2 \times 10$ \\
\hline Psych & USA Network, 2006-2014 & $7 \times 15$ \\
\hline Pushing Daisies & $A B C, 2007-2009$ & $1 \times 02$ \\
\hline Mad Men & AMC, 2007-2015 & $7 \times 07$ \\
\hline Skins & Channel 4, 2007-2013 & $1 \times 09$ \\
\hline Flight of the Conchords & HBO, 2007-2009 & $1 \times 01$ \\
\hline La que se avecina & Telecinco, 2007-2019 & $7 \times 05$ \\
\hline 18, la sèrie & Antena 3, 2008-2009 & $1 \times 01$ \\
\hline Física o química & Antena 3, 2008-2011 & $6 \times 09$ \\
\hline Fringe & Fox, 2008-2013 & $2 \times 20$ \\
\hline Modern family & ABC, 2009-2019 & $1 \times 04$ \\
\hline The middle & $A B C, 2009-2018$ & $8 \times 22$ \\
\hline Marisol, la película & Antena 3, 2009 & $1 \times 01$ \\
\hline The good wife & CBS, 2009-2016 & $5 \times 11$ \\
\hline Glee & Fox, 2009-2015 & $2 \times 07$ \\
\hline Community & NBC, 2009 -2014 y Yahoo!, 2015 & $3 \times 10$ \\
\hline Dance Academy & ABC1, 2010-2013 & $1 \times 01$ \\
\hline Los protegides & Antena 3, 2010-2012 & $2 \times 06$ \\
\hline Raphael: Una historia de superación personal & Antena 3, 2010 & $1 \times 01$ \\
\hline
\end{tabular}


El número musical en las series de televisión: la sincronía musicovisual... | Galeano

\begin{tabular}{|c|c|c|}
\hline Raising Hope & Fox, 2010-2014 & $3 \times 21$ \\
\hline Once Upon a Time & $A B C, 2011-2018$ & $6 \times 20$ \\
\hline American Horror Story & $F X, 2011-2019$ & $4 \times 01$ \\
\hline Rocío Dúrcal, volver a verte & Telecinco, 2011 & $1 \times 01$ \\
\hline Black Mirror & Channel 4, 2011 -2014 y Netflix, 2016-2019 & $1 \times 02$ \\
\hline Bunheads & ABC Family, 2012-2013 & $1 \times 01$ \\
\hline Girls & $\mathrm{HBO}, 2012-2017$ & $5 \times 05$ \\
\hline Smash & NBC, 2012-2013 & $1 \times 05$ \\
\hline Mi gitana & Telecinco, 2012 & $1 \times 01$ \\
\hline Nashville & ABC, 2012-2016 y CMT, 2016-2018 & $1 \times 01$ \\
\hline Super Fun Night & ABC, 2013-2014 & $1 \times 03$ \\
\hline The Golbergs & ABC, 2013-2019 & $2 \times 14$ \\
\hline Vive cantando & Antena 3, 2013-2014 & $1 \times 01$ \\
\hline Orphan Black & BBC America, 2013-2017 & $2 \times 03$ \\
\hline Inside Amy Schumer & Comedy Central, 2013-2016 & $3 \times 02$ \\
\hline Orange Is The New Black & Netflix, 2013-2019 & $6 \times 01$ \\
\hline Mozart in the jungle & Amazon, 2014-2018 & $2 \times 04$ \\
\hline Bienvenidos al Lolita & Antena 3, 2014 & $1 \times 01$ \\
\hline Dreamland & Cuatro, 2014 & $1 \times 01$ \\
\hline The Flash & The CW, 2014-2019 & $3 \times 17$ \\
\hline Empire & Fox, 2015-2019 & $1 \times 01$ \\
\hline Sense8 & Netflix, 2015-2018 & $1 \times 02$ \\
\hline The Magicians & Syfy, 2015-2019 & $2 \times 09$ \\
\hline Crazy Ex-Girlfriend & The CW, 2015-2019 & $1 \times 12$ \\
\hline Younger & TV Land, 2015-2019 & $5 \times 11$ \\
\hline Vinyl & $\mathrm{HBO}, 2016$ & $1 \times 02$ \\
\hline Gilmore Girl: $A$ year in the life & Netflix, 2016 & $1 \times 03$ \\
\hline The get down & Netflix, 2016-2017 & $1 \times 01$ \\
\hline Paquita Salas & Flooxer, 2016-2017 y Netflix, 2018-2019 & $1 \times 04$ \\
\hline Young Sheldon & CBS, 2017-2019 & $1 \times 16$ \\
\hline Riverdale & The CW, 2017-2019 & $2 \times 18$ \\
\hline Pose & FX, 2018-2019 & $1 \times 01$ \\
\hline Arde Madrid & Movistar +, 2018 & $1 \times 04$ \\
\hline Rise & NBC, 2018 & $1 \times 01$ \\
\hline Chilling Adventures of Sabrina & Netflix, 2018 & $2 \times 04$ \\
\hline La casa de las flores & Netflix, 2018-2019 & $1 \times 03$ \\
\hline Luis Miguel: La serie & Netflix, 2018 & $1 \times 01$ \\
\hline Go! Vive a tu manera & Netflix, 2019 & $1 \times 01$ \\
\hline
\end{tabular}

Fuente: elaboración propia. 
Con el propósito de poder llevar a cabo un estudio de casos más profundo, se establecieron las principales características o variables a las que prestar atención durante los procesos tanto de revisión bibliográfica como de análisis y visionado de la muestra. A continuación, se exponen todas las variables estudiadas:

Tabla 6. Variables analizadas en el estudio de casos múltiples.

a) País de origen de la pieza de ficción

b) Tipología de género de la ficción televisiva estudiada (Carrasco, 2010)

- Miniserie

- Antología

- Teleserie

- Teleserie de drama

- Soap opera

- Telenovela

- Serie dramática

o Telecomedia

- Comedia de situación (sitcom)

- Dramedia

c) Target según la clasificación por edades de la plataforma IMDb de la serie analizada

d) Duración media del capítulo

e) Año de emisión del capítulo en su versión original

f) Número de la temporada a la que pertenece el capítulo

g) Número del episodio en la temporada señalada

h) Título del capítulo (si lo tiene)

i) Presencia de un único número musical o de varios en el capítulo analizado

j) Presencia de canto (con letra) y baile (con coreografía no improvisada)

k) Música según tipología 1 (Guijarro y Muela, 2003)

- Música original

- Música preexistente

I) Música según tipología 2 (Guijarro y Muela, 2003; Palencia-Lefler, 2009; y Olarte, 2010)

- Canción original

- Banda sonora o tema instrumental original

- Master o fono

- Cover

- Adaptación

- Música de librería

m) Música según tipología 3 (Alten, 2008)

- Música diegética

○ Voz + instrumentación

o Sólo voz

- Música extradiegética (tanto voz como parte instrumental)

n) Sincronía musicovisual según clasificación a (Leguizamón, 2001)

- Fraseo/rostro/instrumento musical

- Movimiento corporal o de elementos

- Ritmo de montaje 
El número musical en las series de televisión: la sincronía musicovisual... | Galeano

o) Sincronía musicovisual según clasificación b (Chion, 1993; y Rodríguez, 2001)

- Unificadora

- Estética

- Casual

Fuente: elaboración propia.

Una vez obtenida esta información se ha procedido a tabular los datos resultantes y a reagruparlos según cada criterio para realizar un análisis conjunto de los mismos, el cual se expone a continuación en el apartado dedicado a los resultados.

\section{Análisis de los datos: características de los números musicales en las series seleccionadas}

Tras la realización del estudio de los 76 capítulos de series de televisión en los que se encuentran presentes uno o varios números musicales, se han obtenido los resultados que se comentan a continuación.

En cuanto a la primera variable estudiada, no se puede negar que gran parte de la ficción televisiva que encontramos tanto en los canales públicos y privados, como en las plataformas de streaming de España, ha sido producida en Estados Unidos. De hecho, más del 70 por ciento de los casos analizados pertenecen a series que provienen de dicho país. Aun así, aquellas series producidas en España, un 21 por ciento del total, sirven como muestra suficiente para observar qué tipo de números musicales se pueden encontrar en la ficción española. Esta cuestión se retoma al final de este apartado.

De los géneros y formatos señalados en los apartados anteriores se observa representación de todos en los casos estudiados: miniseries, antologías y teleseries, tanto de drama como telecomedias. En la ficción televisiva divisible en episodios el subgénero con mayor representación es la teleserie, siendo éste el formato predominante en 66 casos (87 por ciento de la muestra). A su vez, atendiendo a la clasificación que presenta Carrasco (2010), la naturaleza que se impone en los contenidos es el de la comedia (42 casos) y el formato con mayor presencia es el de la dramedia o dramedy ( 25 casos). Aun así, muy cercano a los valores de la dramedia se halla el formato de teleserie dramática, presente en el 30 por ciento de las series analizadas. Estos datos casan claramente con el target de las piezas de ficción analizadas. De hecho, el perfil del público de la mayoría de estas series es de jóvenes que se inician en la etapa de adolescencia tardía (contenidos para mayores de 16 años). Por ello, no es de extrañar que el género musical que predomine en los temas y canciones interpretados en las series sea el género pop-rock (Quiles y Herrera, 2000), el cual es consumido generalmente por este target.

Precisamente - $\mathrm{y}$ en relación con este target comentado, que es la tercera variable señalada en la metodología - gran parte de la muestra empleada son consideradas como teen series. Masanet y Fedele (2019: 6), definen las series juveniles o teen series como «aquellos productos de ficción seriada protagonizados por personajes adolescentes y dirigidos expresamente a una audiencia juvenil». Algunas características más actuales de estas series son «la predominancia del género dramático y de ciencia ficción, el uso creciente de escenarios 
diferentes de los tradicionales instituto y hogar, y una compleja estrategia transmedia» (Masanet y Fedele, 2019: 7).

No hay una gran diferencia en cuanto a la cantidad de casos en los que se utiliza un único número musical (51 por ciento), frente a aquellos capítulos de series en los que se presentan varios (49 por ciento). De estos últimos 37 casos analizados donde existen más de un número musical por episodio, se entenderán como capítulos especiales aquellos que se den generalmente en series que no tienen relación directa con el género musical y la industria de la música. Es decir, series que por decisiones de sus productores y guionistas hayan decidido realizar un episodio especial con números musicales para homenajear este género $\mathrm{y}$, como se citaba al principio del estudio, incluir recursos nuevos para sorprender a sus seguidores (García, 2013). De hecho, es un recurso fácil para la parodia, la ironía y el humor. Además de que «el número musical se ha convertido en un cliché habitual en la construcción audiovisual para aludir a mundos imposibles y entornos oníricos» (Fraile, 2012: 329). En definitiva, se podrán encontrar tanto capítulos con un único número musical como que contengan varios, siendo esta última opción, un capítulo especial que brindan los productores de la serie a sus seguidores.

Cabe destacar la considerable cantidad existente de series en las que es normal y recurrente el empleo constante de números musicales. En esta investigación se reconoce como serie de género musical o vinculada al mundo musical a todas las ficciones que tratan temas relacionados con el propio género - como Vive Cantando (Antena 3, 2013-2014) y Glee (Fox, 2009-2015) - , grupos de música — Flight of the Conchords (HBO, 2007-2009)-, compañías de teatro musical —Smash (NBC, 2012-2013) —, el mundo del espectáculo y la danza - Un paso adelante (Antena 3, 2002-2005) y Dance Academy (ABC1, 2010-2013)-, orquestas o bandas de música clásica — Mozart in the jungle (Amazon, 2014-2018)-, biopics o documentales que traten la vida de artistas musicales - Luis Miguel: la serie (Netflix, 2018-) - y Mi gitana (Telecinco, 2012) - , la industria fonográfica —Vinyl (HBO, 2016) y Empire (Fox, 2015-2019) —, o géneros musicales concretos — por ejemplo, rap en el caso de la serie The get down, (Netflix, 2016-2017), o country en la serie Nashville (ABC, 2012-2016 y CMT, 2016-2018). Este tipo de series suele incluir varios números musicales en todos sus capítulos. Más del 30 por ciento de los casos analizados forman parte de este conjunto de series de televisión que toman la música como núcleo de las vidas de sus personajes.

En relación con esta cuestión, existe un término dado en el ámbito cinematográfico denominado como backstages musicals, que son aquellas «películas musicales cuyas historias tratan sobre un espectáculo y se centran en las relaciones entre los intérpretes del mismo» (Selva, 2014: 132). Esta cuestión recuerda también a la autonomía de los números musicales en algunas series de televisión, ya que algunas veces estos números no están directamente vinculados a la historia que se está desarrollando durante el episodio.

Precisamente uno de los casos analizados presenta elementos estéticos similares al del videoclip, más allá de su alusión clara al género musical. Al final del capítulo titulado 'Chick or treat' (1x03) dedicado a Halloween en la sitcom de Super Fun Night (ABC, 2013-2014) aparece un movimiento de cámara que se aproxima a la televisión del salón y se adentra en ella 
para dar pie a un número musical en blanco y negro. Suena la canción 'Monster Mash' de Bobby Pickett (The Original Monster Mash, 1962), que da pie a la aparición del elenco disfrazado de la serie protagonizando un número musical grupal donde conviven el canto y la danza en medio de un cementerio. Es decir, se observa en el empleo del número musical por parte de los guionistas y productores la utilización, a veces, de la estética del videoclip.

Prosiguiendo con las variables observadas en los casos estudiados, al centrarnos en la décima variable, la cual hace referencia al empleo del canto y la danza, se observa que en la mayoría de los números musicales analizados los personajes cantan (91 por ciento de los casos) y danzan con una estructura de movimientos o coreografia estudiada previamente (49 por ciento). No se han considerado danzas o coreografias a aquellos movimientos simples realizados por los personajes al ritmo de la música, ya que la mayoría de las veces son improvisados por el actor o actriz que interpreta el papel y con una funcionalidad más expresiva que espectacular o con intención de exhibir un espectáculo. De esta forma, se centra la atención en aquellas coreografias individuales y grupales que recuerdan a las realizadas en las obras musicales clásicas o actuales.

\section{Gráfico 1. Diagrama circular donde se muestran los porcentajes correspondientes a los casos analizados en los que aparece el canto vocal o números de baile de manera conjunta o independiente.}

Números con canto vocal y danza

Números únicamente con danza
Números únicamente con canto vocal

Otros

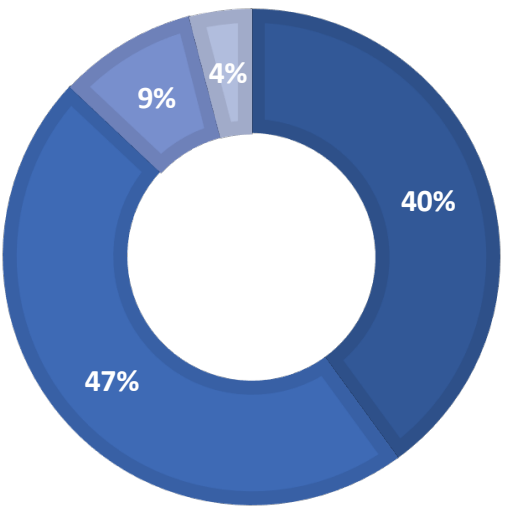

Fuente: elaboración propia.

De hecho, varios capítulos analizados muestran ese homenaje y recreación de números musicales propios de grandes producciones cinematográficas como pueden ser Singin' in the Rain (Gene Kelly y Stanley Donen, 1952). La escena tan emblemática de esta película interpretada por Gene Kelly es recreada por el profesor Will (interpretado por el actor Matthew Morrison) en el séptimo capítulo de la segunda temporada de la serie Glee (2009-2015). El 
tema musical 'Singing in the rain' es adaptado a la actualidad en la serie y al target que la consume, creándose un mash-up o bastard pop ${ }^{6}$ con la canción 'Umbrella' de la cantante pop Rihanna.

También se observa una intención de homenajear al filme musical La la land (Damien Chazelle, 2016) en el vigésimo segundo episodio de la octava temporada de la The Middle (2009-2018). Sue Heck (interpretada por Eden Sher), la hija mediana de la familia, y su amigo Brad protagonizan un número musical en el que no solo mencionan el nombre de los actores protagonistas y el título de esta película musical, sino que además recrean sus principales números de baile.

En la figura número 3 se puede observar la similitud entre ambas piezas audiovisuales. En el episodio de la serie se muestran guiños a la película La ciudad de las estrellas: La la land incluidos en el mismo número musical. Por un lado, en la película un grupo de personas realiza una coreografia interpretando el tema original 'Another day of sun'. Se observa la alusión a esta escena en la participación de múltiples personajes que forman parte del número de danza en el episodio de The Middle.

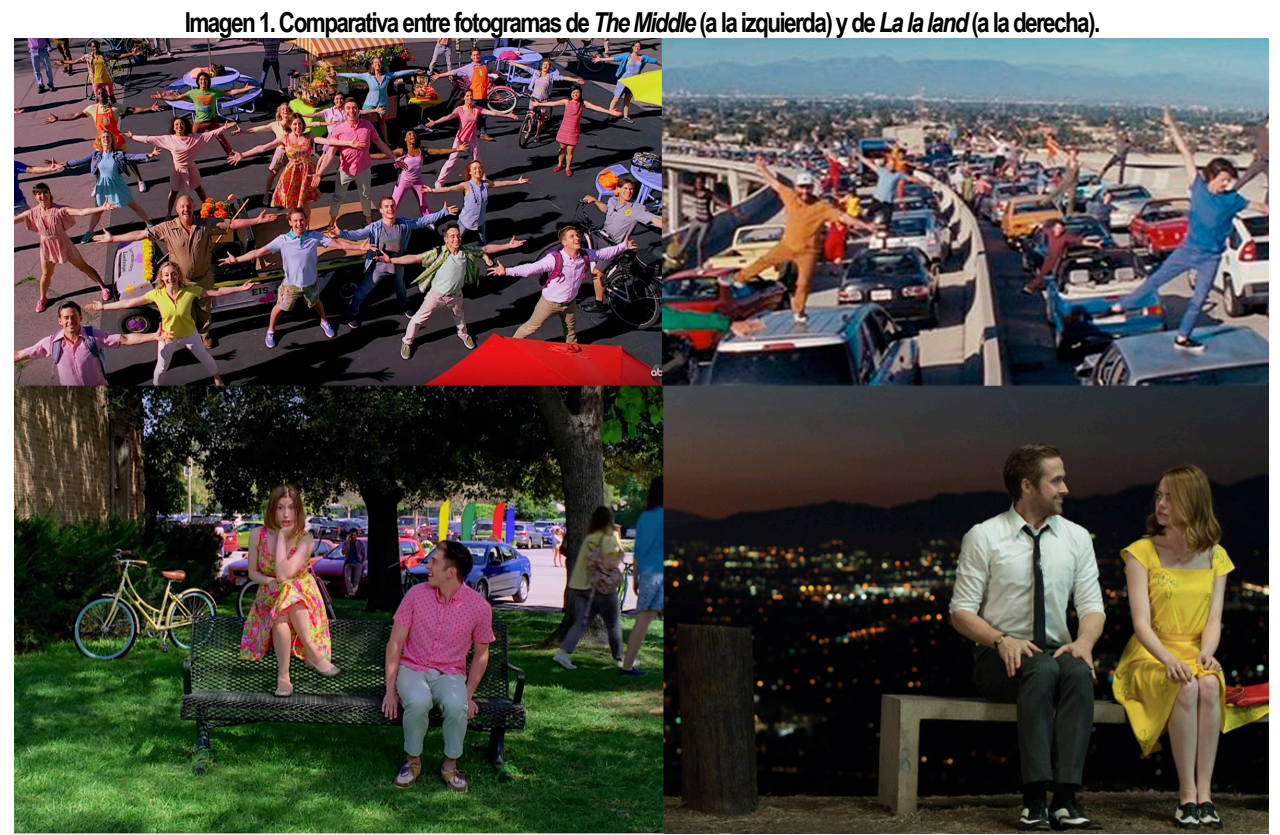

Fuente: fotogramas del capítulo 8x22 de The Middle (ABC, 2009-2018) y La la land (Damien Chazelle, 2016)

\footnotetext{
${ }^{6}$ El bastard pop o mash-up es «un género de música popular basado en un método de producción particular que consiste en la combinación de uno o más temas musicales en una especie de collage». Bastard pop. (s.f.). Recuperado de: https://es.wikipedia.org/wiki/Bastard pop, el 29 de junio de 2019.
} 
A su vez, en la figura se muestran dos fotogramas, tanto de la serie como de la película, en los que se observa una escena originada en ambos casos en un banco donde los personajes cantan y realizan movimientos al ritmo de la música. En el caso del número musical presente en este capítulo la canción también es un tema original compuesto para el episodio titulado 'March to your own drummer'.

Otra de las variables señaladas en la metodología versaba sobre el tipo de música empleado en los números musicales. Se señalaron dos clasificaciones tipológicas principales. Por un lado, dependiendo de si la música existía previamente o no a la producción del capítulo, se podría categorizar como música original o, por el contrario, preexistente. Por otro lado, una segunda clasificación sugería diferentes subtipos de música, siendo estos: canción original, banda sonora o tema instrumental original, fono o master, cover, adaptación y música de librería. En relación con esta cuestión de la tipología de música señalada por Olarte (2010) y empleada en los números musicales analizados, predomina el uso de música preexistente (63 por ciento de los casos) y, más concretamente, el uso del cover. Esta última forma musical está presente en unos 25 casos. Algunos motivos de su empleo han sido ya mencionados por Moschini (2011) anteriormente. A pesar de ello, otro de los motivos al que puede deberse su uso podría ser la intención de mantener cierta correlación con el personaje que canta. De esta forma, no sólo se consigue hacer propia la canción y el tema tratado en la misma, sino que también se consigue mostrar un espectáculo en el que se presentan nuevas cualidades musicales del actor o actriz que el público desconoce en la mayoría de los casos.

En cuanto a la clasificación del tipo tres señalada en esta investigación y centrada en la diferenciación entre la música diegética y la extradiegética, se observa que en más del 90 por ciento de los casos analizados la fuente vocal de la que proviene la música está presente en escena, es decir, se trata de música diegética. Esto se debe a que el personaje que protagoniza el número musical canta, atendiendo a la clasificación presentada por Alten (2008). Sin embargo, únicamente en 21 casos la parte instrumental que acompaña a la voz cantante se encuentra también presente en escena, dejando de ser extradiegética. Los instrumentos que suelen aparecer más en los números musicales analizados son las guitarras clásicas $\mathrm{y}$ acústicas (1x04, Modern family), el piano (2x04, Mozart in the jungle), e instrumentos propios de un grupo de rock como la batería, la guitarra eléctrica y el bajo eléctrico (4x01, Los hombres de Paco).

Como se exponía en la parte teórica de esta investigación, una de las características de estos números musicales es la aparición de puntos síncronos musicovisuales. Si se centra la atención en este fenómeno de la sincronía musicovisual es importante señalar que siempre está presente en todos los números musicales analizados. Según la clasificación establecida por Leguizamón (2001), la cual se centraba en la forma en la que se producía dicha sincronía, más del 80 por ciento de los casos viene originada tanto por el fraseo (labio) y el rostro (muecas al cantar), como por el movimiento corporal de los figurantes y el ritmo del montaje de los planos y secuencias. Otra clasificación señalada en esta investigación fue la presentada por Sedeño (2008), quien diferenciaba entre una sincronía musicovisual unificadora, estética y casual. Se observa en los casos estudiados que en más del 90 por ciento de los números musicales se da 
una sincronía unificadora. Este dato no es de extrañar, puesto que la sincronía unificadora tiende a darse cuando se presenta una música diegética.

A veces, el playback también se encontrará presente en algunos de los números musicales de las series de televisión. Esta reproducción de música anteriormente grabada mientras los artistas cantan o tocan sus instrumentos de manera fingida es un empleo común tanto en el cine musical como en el videoclip (Selva, 2014). Un claro ejemplo de su uso es el capítulo noveno de la sexta temporada de Física o química (Antena 3, 2008-2011). En dicho episodio se realiza un lipdub $b^{7}$ o playback grupal. Se podría considerar como sincronía unificadora, pero el espectador observa que el sonido procede de una fuente que realmente no se ve (y esto se muestra claramente cuando el personaje que frasea y mueve los labios no coincide con quien canta y se escucha). Por ello, se presenta una circunstancia especial ya que la característica principal de la sincronía unificadora, es decir, el empleo de una música diegética, no se manifiesta en dicho ejemplo.

Por último, y con la intención de aprovechar los resultados obtenidos al máximo, se ha decidido centrar la atención en la producción española y su presencia en los casos analizados (más del 20 por ciento del total). Los números musicales dados en los capítulos analizados de las series producidas en España presentan las siguientes características generalmente. En ellos se presentan el mismo número de casos que contienen un único número musical, como varios números musicales. Este último, sobre todo, se encuentra en las series de género musical y en las miniseries analizadas. A pesar de que en España existen varios ejemplos de miniseries sobre biopics de cantantes famosos (por ejemplo, series sobre la vida de Raphael, Isabel Pantoja, Marisol, Rocío Dúrcal, etc.), el formato que predomina es el dramedia o dramedy (50 por ciento de las series españolas analizadas). En estos números musicales se tiende a emplear mayormente la música preexistente, realizándose covers de los temas seleccionados, y se respeta así la letra original y el estilo musical de la canción interpretada.

\section{Bibliografía}

Alten, S. (2008). El sonido en los medios audiovisuales. Andoain: Escuela de Cine y Video.

CALDERÓn, D. (2013). Música y sonido en el 'lipdub’. En GuSTEMS, J. (Ed.). Música y audición en los géneros audiovisuales. Barcelona: Universidad de Barcelona, pp. 169-177.

CARRASCO, A. (2010). Teleseries: géneros y formatos. Ensayo de definiciones. Miguel Hernández Communication Journal, 1, 174-200.

CASCAJOSA, C. (2016). La cultura de las series. Barcelona: Kaplan.

CASCAJOSA, C. (2009). La nueva edad dorada de la televisión norteamericana. Secuencias, 29, 6-31.

\footnotetext{
${ }^{7}$ Se puede definir el lipdub como «un vídeo musical en el cual participan un grupo de personas, cantando y bailando al ritmo de una música preestablecida (que es incorporada posteriormente), y grabado en un formato de plano secuencia» (Calderón, 2013: 170).
} 
CASCAJOSA, C. (2006). No es televisión, es HBO: La búsqueda de la diferencia como indicador de calidad en los dramas del canal HBO. Zer, 11(21), 23-33.

CHION, M. (1993). La audivisión: Introducción a un análisis conjunto de la imagen y el sonido. Barcelona: Paidós comunicación.

FRAILE, T. (2012). Músicas para persuadir: Apropiaciones musicales e hibridaciones genéricas en la publicidad audiovisual. Comunicación, 1 (10), 324-337.

GARCÍA, J. (2013). La inserción del número musical en las series de televisión: El papel de la música en Scrubs. Cuadernos de Etnomusicología, 3, 204-219.

GARCÍA, J. y JOHNSON, S. (2015). Leitmotiv y creación de personajes. La evolución del leitmotiv asociado al personaje de Sira en la serie de ficción El tiempo entre costuras, un primer ejemplo para el análisis musical. Creatividad y Sociedad, (24), 111-137.

GORDILlO, I. (2009). El género ficcional: formatos. En GORDILlO, I. (Ed.). La hipertelevisión: géneros y formatos. Quito-Ecuador: Editorial Ciespal, pp. 99-150.

GuijarRo, T. y MuElA, C. (2003). La música, la voz, los efectos y el silencio en la publicidad: la creatividad en la producción del sonido. Madrid: CIE Dossat 2000.

LEGUIZAMÓn, J. A. (2001). Exploraciones musicovisuales. Cuadernos, Revista Facultad de Humanidades y Ciencias Sociales de San Salvador de Jujuy, 17, 251-269. Argentina.

LLINARES, F. (2013). La dimensión sonora de los tráileres. En GUSTEMS, J. (Ed.). Música y audición en los géneros audiovisuales. Barcelona: Universidad de Barcelona, pp. 155-167.

MASANET, M. J. y FeDELE, M. (2019). El "chico malote" y la "chica responsable": modelos aspiracionales y representaciones juveniles en las teen series españolas. Palabra Clave, 22(2).

MoschINI, I. (2011). Music and series: the verbalizing role of soundtrack lyrics from TV series to user-generated narrations. Visual Communication, 10(2), 193-208.

OLARTE, M. (2005). El género del musical y la utilización de sus melodías con fines expresivos. En Olarte Martínez, M. (Ed.). La música en los medios audiovisuales: Algunas aportaciones. Salamanca: Plaza Universitaria, pp.101-118.

OLARTE, M. (2010). Nuevos retos para la música en la televisión: Ficción y no ficción. Trípodos, 26, 39-51.

PADILlA, G. y REQUEIJO, P. (2011). Las series de televisión como nuevo vehículo publicitario de la música: Los casos de Disney Channel y Elexandra Patsavas. index.comunicación, 1, 69-87.

PALENCIA-LEFLER, M. (2009). La música en la comunicación publicitaria. Comunicación y Sociedad, 22(2), 89-108.

QUILES, O. y HERRERA, L. (2000). Análisis educativo-musical del medio televisión. Comunicar, 15, 169-174.

RODRÍGUEZ, Á. (2001). La dimensión sonora del lenguaje audiovisual. Barcelona: Paidós Ibérica. 
SEDEÑO, A. M. (2008). La relación musicovisual en el videoclip. Propuestas metodológicas y tipología. En de AGUILERA, M.; AdELl, J. E y SEDEÑO, A. (Eds.), Comunicación y música I: Lenguaje y medios. Barcelona: UOC, pp. 121-140.

SELVA, D. (2014). El videoclip: comunicación comercial en la industria musical. Sevilla: Alfar Universidad.

STILwELL, R. (2003). It May Look Like a Living Room...: The Musical Number and the Sitcom. ECHO, 5(1).

ZuAZU, M. y LóPEZ, R. (2014). Las músicas de Betty, la fea. Latin American Music Review, 35 (1), 1-24. televisión: la sincronía musicovisual como característica principal de la escena musical. index.comunicación, 9(3), 115-138. 